\title{
ROLE OF MONTHLY CHECK UP OF BLOOD PRESSURE IN A FREE HEALTH CAMP (A FIFTEEN YEARS FOLLOW UP STUDY)
}

\author{
Dipankar Deb1, Manmath Nath², Satyaranjan Bhattacharjee ${ }^{3}$
}

${ }_{1}^{1}$ Associate Professor, Department of General Medicine, Silchar Medical College, Silchar.

2Retired Professor \& HOD, Department of Cardiology, Silchar Medical Collage, Silchar.

${ }^{3}$ Retired Professor, Department of General Medicine, Silchar Medical College, Silchar.

ABSTRACT
BACKGROUND
Cardiovascular disease is one of the commonest cause of death worldwide. High blood pressure increases the risk of
cardiovascular disease. Even in the developed countries, most of the patient with high blood pressure are unaware of their high
blood pressure and not under medication; $25 \%$ rural Indians are hypertensive. Of these, 25\% rural Indians are aware of their
hypertensive status. Only $25 \%$ rural Indians are being treated for hypertension. One-tenth of rural and one-fifth of urban Indian
hypertensive population have their BP under control.(1)

\section{OBJECTIVES}

1. To detect the hypertensive patient amongst the adult attended, the free health camp on $6^{\text {th }}$ June 2001.

2. Follow up all the detected hypertensives on $4^{\text {th }}$ Sunday of every month with a target to keep the blood pressure systolic below $140 \mathrm{mmHg}$ and diastolic below $90 \mathrm{mmHg}$ by providing free medicine and necessary advice from the Charitable Heart Care Centre, Udarbond.

3. To see the effect of long-term follow up of these patients and to detect complications if any.

\section{METHODS}

A free health camp was organised on $6^{\text {th }}$ June 2001 at village Udarbond of Cachar District of Assam. Hypertensive patients were detected from the adult attended the free camp. They were asked to attend the Charitable Heart Care Centre every 4 th Sunday for regular check up of their blood pressure and to take the necessary medicine and advice free.

\section{RESULTS}

Of the total 250 (150 males and 100 females) adults attended the free health camp, 50 (20\%) were hypertensive. Of the 150 males $30(20 \%)$ and of the 100 females $20(20 \%)$ were hypertensive. After 15 years follow up, out of 30 males 3 (10\%) died and 2 (6.66\%) dropped out. Of the 30 males, 1 (3.33\%) died of myocardial infarction, 1 (3.33\%) died of cerebral stroke and 1 (3.33\%) died of cerebral malaria. Of the 20 females, 2 (10\%) died of cerebral stroke and 3 (15\%) dropped out. Of the 50 hypertensives, 40 (80\%) are attending the camp till date. Of the 30 males 25 (83.33\%) and of 20 females 15 (75\%) are still surviving; 16 (53.33\%) of 30 males attended the health camp on $6^{\text {th }}$ June 2001 and 16 (64\%) of 25 males presently attending the camp and 10 (50\%) of 20 female hypertensives on $6^{\text {th }}$ June 2001 and $10(66.66 \%)$ of 15 females presently attending the camp achieved the target blood pressure systolic below $140 \mathrm{mmHg}$ and diastolic below $90 \mathrm{mmHg}$. Total 26 (52\%) of 50 hypertensives on 6th June 2001 and 26 (65\%) of 40 patients attending the camp regularly till date could achieve the target blood pressure.

\section{CONCLUSION}

From the above study, it is concluded that regular monthly check up of blood pressure and its treatment and advice could keep blood pressure under control and lower the incidence of CVDs death due to hypertension.

\section{KEYWORDS}

Hypertension, India, Rural, Monthly.

HOW TO CITE THIS ARTICLE: Deb D, Nath M, Bhattacharjee S. Role of monthly check up of blood pressure in a free health camp (a fifteen years follow up study). J. Evolution Med. Dent. Sci. 2016;5(20):1009-1012, D0I: 10.14260/jemds/2016/235

\section{INTRODUCTION}

About 33\% urban and 25\% rural Indians are hypertensive. Of these, $25 \%$ rural and $42 \%$ urban Indians are aware of their hypertensive status. Only $25 \%$ rural and $38 \%$ of urban Indians are being treated for hypertension.

Financial or Other, Competing Interest: None.

Submission 26-01-2016, Peer Review 22-02-2016,

Acceptance 27-02-2016, Published 09-03-2016.

Corresponding Author:

Dipankar Deb,

Associate Professor,

Department of General Medicine,

Silchar Medical College,

Sichar-788014.

E-mail: dr.dipankardebcardio@gmail.com

DOI: $10.14260 /$ jemds $/ 2016 / 235$
One-tenth of rural and one-fifth of urban Indian hypertensive population have their BP under control.(1) Previously, a systematic review on the prevalence of HTN in India for studies published between 1969 and July 2011, reported a range between 13.9 to $46.3 \%$ and 4.5 to $58.8 \%$ in urban and rural areas of India, respectively.(2)

In an analysis of worldwide data for the global burden of HTN, $20.6 \%$ of Indian men and $20.9 \%$ of Indian women were suffering from HTN in 2005.(3) Recent studies from India have shown the prevalence of HTN to be $25 \%$ in urban and $10 \%$ in rural people in India. $(4,5,6,7)$ Hypertension (HTN) exerts a substantial public health burden on cardiovascular health status and healthcare systems in India. $(8,9)$ It is estimated that by 2020, CVDs will be the largest cause of mortality and morbidity in India.(10) 
Hypertension is a major risk factor for CVDs including stroke and myocardial infarction and its burden is increasing disproportionately in developing countries, as they undergo demographic transition. $(11,12,13)$

Using a cut-off of $140 \mathrm{mmHg}$ or greater systolic Blood Pressure (BP) or $90 \mathrm{mmHg}$ or greater diastolic BP, the agestandardised prevalence of hypertension worldwide in the year 2000 was estimated to be $26.6 \%$ in men (95\% confidence interval, CI 26.0 to 27.2 ) and $26.1 \%$ in women (95\% CI 25.5 to 26.6). This was estimated to rise to $29.0 \%$ in men (95\% CI 28.6 to 29.4 ) and $29.5 \%$ in women (95\% CI 29.1 to 29.9) by 2025. Hypertension (HTN) is directly responsible for $57 \%$ of all stroke deaths and $24 \%$ of all Coronary Heart Disease (CHD) deaths in India.(4)

\section{Aim of the Study are}

1. To detect the patient with hypertension amongst the adult patients attended the free health camp organised on $6^{\text {th }}$ June 2001 in the village of Udarbond in the Cachar district of Assam by the Charitable Heart Care Centre of table tennis club as a part of their social service.

2. To follow up all the hypertensive patients monthly on $4^{\text {th }}$ Sunday of every month.

3. To do ECG and some preliminary test free of cost.

4. To provide them free medicine and advice from the charitable heart care centre.

5. To see the effect of regular check-up blood pressure and its treatment.

6. To detect the complications of hypertension if any.

\section{MATERIALS AND METHODS}

Period of Study: From $6^{\text {th }}$ June 2001 to till date.

Place of Study: Charitable Heart Care Centre of Table Tennis Club of Udarbond.

Follow up: Monthly follow up on $4^{\text {th }}$ Sunday of every month. Investigation: Routine investigation, Urine Blood Sugar, Blood Urea, S. Creatinine, ECG.

Medication: Free medicine was provided from the centre. Source of Medication: Physician sample provided by various pharmaceutical companies, physician sample collected from local physician, physician sample collected by Ramakrishna Mission Silchar and donated to the centre and sometimes medicine was purchased by the centre from their fund.

\section{Inclusion Criteria}

Patient above 30 years of age with blood pressure systolic above $140 \mathrm{mmHg}$ and diastolic above 90 .

\section{Exclusion Criteria}

Patient with,

1. Diabetes

2. Kidney Disease.

3. Stroke.

4. Ischaemic Heart Disease.

5. CHF.

6. COPD.

\section{WERE EXCLUDED FROM THE PRESENT STUDY Target Blood Pressure}

Target blood pressure was systolic below $140 \mathrm{mmHg}$ and diastolic below $90 \mathrm{mmHg}$.

\section{Control Group for Comparison}

For ethical reason control group of patients with hypertension who will be without medication were not kept.

\section{Compliance}

Compliance was determined that those patients came to the camp on every $4^{\text {th }}$ Sunday for BP check-up, medication and advice. Absence for two or more consecutive months was considered as noncompliance. Medicine were supplied for whole one month as per need of patient.

\section{Drug Protocol}

Medicine were supplied as per need of the patients (Tailormade protocol). Mostly Hydrochlorothiazide, Amlodipine, Beta Blocker, ARV and ACE inhibitors were used.

\section{Resistant Hypertension}

Those patients who could not achieve the target blood pressure after receiving 3 drugs with different mechanism of action, one being thiazide diuretic.

\section{Result and Observations}

Doctors present in the Health Camp on $6^{\text {th }}$ June 2001.

Dr. Dipankar Deb, then Registrar of Cardiology SMCH, now Associate Professor of Medicine SMCH.

Dr. M. Nath, Retd. Professor and HOD of Cardiology, SMC.

Dr. S.R. Bhattacharjee, Retd. Professor of Medicine, SMC.

Total no of patients present in the free health camp on $6^{\text {th }}$ June 2001: 250 (Male-150, Female-100).

Total no. of patients detected to be hypertensive:- 50 (20\%) Male $30(20 \%)$ and Female $20(20 \%)$.

All the patients with hypertension were advised to come to the centre every month on $4^{\text {th }}$ Sunday for check-up and for collection of medicine.

\section{Patient Profile}

\begin{tabular}{|c|c|c|c|}
\hline Age Group & $\begin{array}{c}\text { Male } \\
\text { N-30 }\end{array}$ & $\begin{array}{c}\text { Female } \\
\text { N-20 }\end{array}$ & $\begin{array}{c}\text { Total } \\
\text { N-50 }\end{array}$ \\
\hline $\begin{array}{c}30 \text { to } 40 \\
\text { yrs. }\end{array}$ & $1(3.33 \%)$ & Nil & $1(2 \%)$ \\
\hline $\begin{array}{c}41 \text { to } 50 \\
\text { yrs. }\end{array}$ & $5(16.66 \%)$ & $2(10 \%)$ & $7(14 \%)$ \\
\hline $\begin{array}{c}51 \text { to } 60 \\
\text { yrs. }\end{array}$ & $10(33.33 \%)$ & $10(50 \%)$ & $20(40 \%)$ \\
\hline $\begin{array}{c}61 \text { to } 70 \\
\text { yrs. }\end{array}$ & $8(26.66 \%)$ & $4(20 \%)$ & $12(24 \%)$ \\
\hline $\begin{array}{c}\text { Above } 71 \\
\text { yrs. }\end{array}$ & $6(20 \%)$ & $4(20 \%)$ & $10(20 \%)$ \\
\hline \multicolumn{4}{|c|}{ Table 1: Profile of Hypertensive Patients } \\
\hline
\end{tabular}

Blood pressure ranges of the selected patients are shown in Table No. II.

\begin{tabular}{|c|c|c|c|}
\hline B.P. Range & $\begin{array}{c}\text { Male } \\
\text { N-30 }\end{array}$ & $\begin{array}{c}\text { Female } \\
\text { N-20 }\end{array}$ & $\begin{array}{c}\text { Total } \\
\text { N-50 }\end{array}$ \\
\hline $\begin{array}{c}140-159 / 90-99 \\
\mathrm{mmHg}\end{array}$ & $10(33.33 \%)$ & $8(40 \%)$ & $\begin{array}{c}18 \\
(36 \%)\end{array}$ \\
\hline $\begin{array}{c}160-179 / 100- \\
109 \mathrm{mmhg}\end{array}$ & $15(50 \%)$ & $10(50 \%)$ & $\begin{array}{c}25 \\
(50 \%)\end{array}$ \\
\hline $\begin{array}{c}\text { Above } \\
180 / \text { above } 110 \\
\text { mmHg }\end{array}$ & $5(16.66 \%)$ & $2(10 \%)$ & $7(14 \%)$ \\
\hline \multicolumn{4}{|c|}{ Table 2: Showing the Blood Pressure Range } \\
\hline
\end{tabular}


Total no. of initial 50 hypertensive patients attending the free health camp after 15 years 40 (80\%), Male-25, Female-15.

\begin{tabular}{|c|c|c|c|}
\hline Age Group & Male (25) & Female (15) & Total (40) \\
\hline $\begin{array}{c}45 \text { to } 55 \\
\text { yrs. }\end{array}$ & $6(24 \%)$ & $6(40 \%)$ & $12(30 \%)$ \\
\hline $\begin{array}{c}56 \text { to } 65 \\
\text { yrs. }\end{array}$ & $10(40 \%)$ & $6(40 \%)$ & $16(40 \%)$ \\
\hline $\begin{array}{c}66 \text { to } 75 \\
\text { yrs. }\end{array}$ & $5(20 \%)$ & $2(13.33 \%)$ & $7(17.5 \%)$ \\
\hline $\begin{array}{c}76 \text { to } 85 \\
\text { yrs. }\end{array}$ & $4(16 \%)$ & $1(6.66 \%)$ & $5(12.5 \%)$ \\
\hline $\begin{array}{c}\text { Above } 86 \\
\text { yrs. }\end{array}$ & Nil Nil & Nil \\
\hline \multicolumn{2}{|c|}{ Table 3: Patient's Profile after 15 years } \\
\hline \multicolumn{4}{|c}{} \\
\hline
\end{tabular}

Total nos. of patients died during 15 years follow up 5 (10\%) (Male-3, Female 2). Cause of Death out of 30 males, 3 died (10\%).

a. Acute myocardial infarction in 1 (3.33\%).

b. Stroke in $1(3.33 \%)$.

c. Cerebral Malaria $1(3.33 \%)$.

Out of 20 females, 2 died (10\%), both died of stroke.

Total no. of patients dropped out during 15 years follow up 5 (10\%) (Male-2, Female-3).

Blood pressure profile of 40 patients attending monthly free health camp is shown in Table IV.

\begin{tabular}{|c|c|c|c|}
\hline Blood Pressure & $\begin{array}{c}\text { Male } \\
\mathbf{N}-25\end{array}$ & $\begin{array}{c}\text { Female } \\
\mathbf{N}-15\end{array}$ & $\begin{array}{c}\text { Total } \\
\mathbf{N}-40\end{array}$ \\
\hline $\begin{array}{c}120-139 / 80-89 \\
\mathrm{mmHg}\end{array}$ & $\begin{array}{c}16 \\
(64 \%)\end{array}$ & $\begin{array}{c}10 \\
(66.66 \%)\end{array}$ & $\begin{array}{c}26 \\
(65 \%)\end{array}$ \\
\hline $\begin{array}{c}140-159 / 90-99 \\
\mathrm{mmHg}\end{array}$ & $\begin{array}{c}8 \\
(32 \%)\end{array}$ & $\begin{array}{c}4 \\
(26.66 \%)\end{array}$ & $\begin{array}{c}12 \\
(30 \%)\end{array}$ \\
\hline $\begin{array}{c}160-179 / 100-109 \\
\mathrm{mmHg}\end{array}$ & $1(4 \%)$ & $1(6.66 \%)$ & $2(5 \%)$ \\
\hline $\begin{array}{c}\text { Above } 180 / 110 \\
\mathrm{mmHg}\end{array}$ & $\mathrm{Nil}$ & $\mathrm{Nil}$ & $\mathrm{Nil}$ \\
\hline \multicolumn{3}{|c|}{$\begin{array}{c}\text { Table 4: Blood Pressure profile of 40 Patients } \\
\text { attending Monthly free Health Camp }\end{array}$} \\
\hline
\end{tabular}

\section{Compliance}

$40(80 \%)$ of 50 patients are compliant. They attended the camp regularly on every $4^{\text {th }}$ Sunday and taking the medicine.

\section{Responder}

$64 \%$ of male and $66.66 \%$ of female could achieve the target blood pressure and $36 \%$ of male and $33.33 \%$ female were resistant.

\section{DISCUSSION}

In the present study, it was found that $50(20 \%)$ of 250 adult patients attended free health camp on $6^{\text {th }}$ June 2001 at village Udarbond in Cachar District of Assam were found to be hypertensive blood pressure above $140 \mathrm{mmHg}$ systolic and above $90 \mathrm{mmHg}$ diastolic. This finding corroborate with the findings of Raghupathy et al.(1) that $25 \%$ of rural Indians are hypertensive. The present study also corroborate with the findings of Kearney PM, et al.(3) who reported $20.6 \%$ of Indian men and $20.9 \%$ of Indian women to be hypertensive. Devi P, et al. reported hypertension in 4.5 to $58.8 \%$ of rural Indians.(2) Considering the target blood pressure systolic below 140
mmHg and diastolic below $90 \mathrm{mmHg} 26$ (52\%) of 50 hypertensives detected on $6^{\text {th }}$ June 2001 and 26 (65\%) of 40 patients attending the camp regularly on $4^{\text {th }}$ Sunday of every month till date could achieve the target blood pressure systolic below $140 \mathrm{mmHg}$ and diastolic below $90 \mathrm{mmHg}$. Although Raghupathy et al.(1) reported only one-tenth of the rural Indian hypertensives have their blood pressure under control. The findings of the present study suggest that regular blood pressure check up and its treatment could help maintain the blood pressure under control.

Hypertension is a major risk factor for CVDs including stroke and myocardial infarction and its burden is increasing in developing countries as they undergo demographic transition.(11,12,13) However, in the present study follow up of 50 (30 males and 20 females) hypertensive for 15 years from $6^{\text {th }}$ June 2001 on every $4^{\text {th }}$ Sunday and check up of their blood pressure and to provide appropriate treatment and advice could reduce the incidence of stroke and myocardial infarction. One $(3.33 \%)$ of 30 male hypertensives died of myocardial infarction and $1(3.33 \%)$ of 30 males died of stroke; 2 (10\%) of 20 females died of stroke. It suggests that regular check up of blood pressure and appropriate treatment and advice could reduce the incidence of CVDs death in hypertensives.

\section{SUMMARY AND CONCLUSION}

From the present study, it is concluded that the incidence of hypertension in the village Udarbond of Cachar District of Assam is same as other part of rural India. Regular monthly check up of blood pressure and appropriate treatment and advice help to keep the blood pressure under control and lower the incidence of CVDs death in hypertensives.

\section{ACKNOWLEDGEMENT}

We express sincere thanks to all the members of Charitable Heart Care Centre of Udarbond and also to Ramakrishna Mission Silchar and all members who helped us by providing medicines to run the free health camp.

\section{REFERENCES}

1. Raghupathy Anchala, Nanda K Kannuri, Hira Pant, et al. Hypertension in India: a systemic review and metaanalysis of prevalence, awareness and control of hypertension. J Hypertens 2014;32(6):1170-1177.

Published online 2014 Apr 30. doi: 10.1097/HJH.0000000000000146 PMCID: PMC4011565.

2. Devi P, Rao M, Sigamani A, et al. Prevalence, risk factors and awareness of hypertension in India: a systematic review. J Hum Hypertens 2013;27:281-287.

3. Kearney PM, Whelton M, Reynolds K, et al. Global burden of hypertension: analysis of worldwide data. Lancet 2005;365:217-223.

4. Gupta R. Trends in hypertension epidemiology in India. J Hum Hypertens 2004;18:73-78.

5. Thankappan KR, Sivasankaran S, Sarma PS, et al. Prevalence-correlates-awareness-treatment and control of hypertension in Kumarakom, Kerala: baseline results of a community-based intervention program. Indian Heart J 2006;58:28-33.

6. Gupta R. Meta-analysis of prevalence of hypertension in India. Indian Heart J 1997;49:450. 
7. Das SK, Sanyal K, Basu A. Study of urban community survey in India: growing trend of high prevalence of hypertension in a developing country. Int J Med Sci 2005;2:70-78.

8. Leeder S, Raymond S, Greenberg H, et al. A race against time. The challenge of cardiovascular disease in developing economies. New York: Columbia university, 2004.

9. Srinath Reddy K, Shah B, Varghese C, et al. Responding to the threat of chronic diseases in India. Lancet 2005;366:1744-1749.

10. The world health report 2002: Reducing risk, promoting healthy life. Geneva, Switzerland: world health organization. World health organization 2002.
11. O'Donnell MJ, Xavier D, Liu L, et al. Risk factors for ischaemic and intracerebral haemorrhagic stroke in 22 countries (the INTERSTROKE study): a case-control study. Lancet 2010;376:112-123.

12. Yusuf S, Hawken S, Ounpuu S, et al. Effect of potentially modifiable risk factors associated with myocardial infarction in 52 countries (the INTERHEART study): case-control study. Lancet 2004;364:937-52.

13. Murray CJL, Lopez AD. Alternative projections of mortality and disability by cause 1990-2020: global burden of disease study. Lancet 1997;349:1498-504. 